\title{
Differences in Physiological Response to Exercise in Patients With Different COPD Severity
}

\author{
Ryoji Maekura MD PhD, Toru Hiraga MD, Keisuke Miki MD, Seigo Kitada MD, \\ Kenji Yoshimura MD, Mari Miki MD, and Yoshitaka Tateishi MD
}

\begin{abstract}
BACKGROUND: Patients with COPD have reduced exercise tolerance associated with dyspnea. This exercise intolerance is primarily due to impaired ventilatory mechanics, but it is also associated with a combination of factors, including inefficient gas exchange, lactic acidosis at a low work rate, and exercise-induced hypoxemia. The survival prognosis of COPD patients with severely reduced exercise capacity is extremely poor, but the pathophysiology of these patients during exercise remains to be accurately established. The present study aimed to characterize life-threatening factors such as hypoxemia, acidosis, and sympathetic activation during exercise in these patients. METHODS: We monitored changes in life-threatening factors and compared these factors among quartile groups, defined according to their peak oxygen uptake status. Ninety-one COPD subjects (82 males, 9 females, average age $69.7 \pm 6.8$ y) consecutively underwent incremental cardiopulmonary exercise testing using a cycle ergometer. Arterial blood gases, lactate, and catecholamines were measured during cardiopulmonary exercise testing. RESULTS: The pathophysiology of the COPD differed among the 4 subject groups. Subjects with the most severely reduced exercise capacity (peak oxygen uptake $\leq 623 \mathrm{~mL} / \mathrm{min}$ ) were characterized by exercise-induced steep decrease in $\mathrm{P}_{\mathrm{aO}}$ slope $(-78 \pm 70 \mathrm{~mm} \mathrm{Hg} / \mathrm{L} / \mathrm{min})$, rapid progression of respiratory acidosis, little change in lactic acidosis, and sympathetic activation at low-intensity work load (plasma norepinephrine $1.41 \pm 0.94 \mathrm{ng} / \mathrm{mL}$ at 20 watts work load), in addition to the limitation of increase in ventilation and impaired gas exchange. CONCLUSIONS: The mechanisms of exercise intolerance in COPD patients significantly differed among subjects with different exercise capacities. Subjects with the most severely reduced exercise capacity had the characteristics of exercise-induced hypoxemia, sympathetic overactivity, and progressive respiratory acidosis at low-intensity exercise. These lifethreatening pathophysiological conditions could be improved by medication and/or pulmonary rehabilitation. Key words: COPD; cardiopulmonary exercise testing; hypoxemia; sympathetic overactivity; acidosis; peak oxygen uptake. [Respir Care 2014;59(2):252-262. (C) 2014 Daedalus Enterprises]
\end{abstract}

\section{Introduction}

Patients with COPD have reduced exercise tolerance. Exertional dyspnea (breathlessness) is a symptom that

The authors are affiliated with the Department of Respiratory Medicine, National Hospital Organization Toneyama Hospital, Toyonaka City, Osaka, Japan.

This study was supported by grants from the Health and Labour Sciences Research Organization and the Osaka Tuberculosis Research Foundation. The funders had no role in study design, data collection and analysis, or preparation of the manuscript. The authors have disclosed no conflicts of interest. makes COPD patients stop prematurely during exercise. The survival prognosis of COPD patients with severely reduced exercise capacity is extremely poor. While the

Ryoji Maekura MD presented a version of this paper at the Annual Congress of the European Respiratory Society, held September 24-28, 2011, in Amsterdam, The Netherlands.

Correspondence: Ryoji Maekura MD, Department of Respiratory Medicine, National Hospital Organization Toneyama Hospital, 5-1-1 Toneyama, Toyonaka City, Osaka 560-0045, Japan. E-mail: rmaekura@toneyama.go.jp.

DOI: $10.4187 /$ respcare.02201 
reduced exercise capacity is not directly life-threatening, associated factors such as hypoxemia, acidosis, and sympathetic activation can increase the mortality risk in such patients. ${ }^{1-7}$ With proper intervention, medication, and/or pulmonary rehabilitation, including exercise training and occupational therapy in daily living, survival prognosis can be improved. Unfortunately, the pathophysiology during exercise of COPD patients is not adequately established.

Exercise intolerance in COPD patients is primarily due to impaired ventilatory mechanics, but it is also associated with gas exchange limitation, cardiovascular factors, skeletal-muscle dysfunction, and other factors. ${ }^{8,9}$ Gas-exchange factors involve impaired ventilation-perfusion relationships that lead to hypoxemia, impaired oxygen delivery, and pulmonary hypertension. The severity of dyspnea rapidly increases at work rates above the lactic threshold, and plasma norepinephrine and epinephrine also increase in a similar manner during exercise. ${ }^{10,11}$ However, we have observed that in some COPD patients with severely reduced exercise capacity, lactic threshold cannot be detected methodologically by estimating the concentration of plasma lactate using the log-log transform of the lactateoxygen uptake relationships in cardiopulmonary exercise testing in clinical practice. ${ }^{12}$

Peak oxygen uptake during incremental cardiopulmonary exercise testing, $\mathrm{FEV}_{1}$, and body mass index (BMI) are predictors of mortality in COPD patients. ${ }^{13-15}$ In a previous report, ${ }^{13}$ the 5 -year survival rate of patients with the most severely reduced peak oxygen uptake $(<654 \mathrm{~mL} /$ min) was $45 \%$ on dividing into quartile groups. The variation among individual COPD patients underpins the need for personalized intervention. However, an improved understanding of COPD pathophysiology is a prerequisite of such intervention and improvement in survival prognosis. The present study aimed to investigate relationships between, and changes in, life-threatening factors such as hypoxemia, acidosis, and sympathetic activation in COPD patients during exercise, and to compare these among the quartile groups divided on the basis of peak oxygen uptake, especially in patients with severely reduced exercise capacity whose survival prognosis is extremely poor.

\section{Methods}

This study was approved by the institutional review board of the National Hospital Organization National Toneyama Hospital and complied with international guidelines for studies involving humans. All subjects gave informed consent.

\section{Subjects}

We recruited consecutive, first-visit COPD out-patients who visited our institution and had exertional dyspnea

\section{QUICK LOOK}

\section{Current knowledge}

Patients with COPD have reduced exercise tolerance because of dyspnea, impaired ventilatory mechanics, and hypoxemia. Reduced exercise capacity is associated with poor outcome.

\section{What this paper contributes to our knowledge}

Exercise intolerance varied with exercise capacity. Severely reduced exercise capacity was characterized by hypoxemia, sympathetic over-activity, and respiratory acidosis at low-intensity exercise.

(modified Medical Research Council dyspnea score $\geq 1$ ) between June 2000 and February 2006. ${ }^{16,17}$ All subjects had a history of cigarette smoking (at least 40 pack-years), and an $\mathrm{FEV}_{1} / \mathrm{FVC}$ of $<0.7$, measured 20 min after the inhalation of salbutamol. We excluded patients with: comorbidities (eg, cardiovascular or neuromuscular disease) that could contribute to dyspnea and exercise limitation; history of asthma, allergic rhinitis, or atopy; eosinophil count $\geq 600$ cells $/ \mu \mathrm{L}$; on an anti-allergic drug or antihistamine drug; active tuberculosis or definite sequelae of tuberculosis; or history of lung resection. Potential study subjects were monitored for 2 months to determine their eligibility for the study, and were prescribed appropriate medication. We also excluded patients with important contraindications to clinical exercise testing, ${ }^{9}$ a history of coronary artery disease, COPD exacerbation within the past 2 months, and patients participating in a pulmonary rehabilitation program.

\section{Pulmonary Function Test and Cardiopulmonary Exercise Testing}

Post-bronchodilator spirometry (Autospirometer System 9, Minato Medical Science, Osaka, Japan) was according to the recommendations of the American Thoracic Society. ${ }^{18,19}$ All spirometric tests were conducted in triplicate, and the highest measurements were used for analyses. In the bicycle ergometer exercise testing, all subjects began unloaded pedaling for $2 \mathrm{~min}$, and then progressive increments of 10 watts every $2 \mathrm{~min}$, as previously described. ${ }^{20,21}$ Expired gas data were collected breath by breath (Vmax, SensorMedics, Yorba Linda, California). We recorded heart rate, breathing frequency, tidal volume, minute ventilation, oxygen uptake, ventilatory equivalent for oxygen, ventilatory equivalent for carbon dioxide, and oxygen pulse. Progressive incremental exercise testing was discontinued when the subject displayed breathlessness 
Table 1. Baseline Data From 91 Subjects With COPD

\begin{tabular}{|c|c|c|c|c|c|}
\hline & \multicolumn{4}{|c|}{ Peak Oxygen Uptake Range, $\mathrm{mL} / \mathrm{min}$} & \multirow{2}{*}{$P^{*}$} \\
\hline & $\begin{array}{l}318-623 \\
\text { Group A }\end{array}$ & $\begin{array}{l}665-803 \\
\text { Group B }\end{array}$ & $\begin{array}{c}829-1,037 \\
\text { Group C }\end{array}$ & $\begin{array}{c}1,040-1,487 \\
\text { Group D }\end{array}$ & \\
\hline Number of subjects & 22 & 23 & 23 & 23 & \\
\hline Age, y & $70.8 \pm 6.7$ & $68.9 \pm 8.3$ & $69.5 \pm 6.9$ & $68.9 \pm 6.1$ & .87 \\
\hline Male/female, no. & $18 / 4$ & $20 / 3$ & $21 / 2$ & $23 / 0$ & \\
\hline Body weight, $\mathrm{kg}$ & $47.8 \pm 7.8$ & $53.7 \pm 7.2$ & $58.6 \pm 12.9$ & $62.6 \pm 7.8$ & $<.001$ \\
\hline Body mass index, $\mathrm{kg} / \mathrm{m}^{2}$ & $18.8 \pm 2.6$ & $20.2 \pm 3.1$ & $22.1 \pm 4.6$ & $22.9 \pm 3$ & $<.001$ \\
\hline $\mathrm{FEV}_{1}, \mathrm{~L}$ & $0.76 \pm 0.23$ & $1.02 \pm 0.28$ & $1.00 \pm 0.35$ & $1.54 \pm 0.52$ & $<.001$ \\
\hline $\mathrm{FEV}_{1}, \%$ predicted & $31.5 \pm 9.1$ & $39.5 \pm 10.6$ & $38.8 \pm 15.3$ & $57.4 \pm 19.3$ & $<.001$ \\
\hline FVC, $\%$ predicted & $82.9 \pm 16.0$ & $94.1 \pm 12.8$ & $83.1 \pm 14.6$ & $105.0 \pm 22.2$ & $<.001$ \\
\hline Heart rate, beats/min & $84.6 \pm 14.8$ & $85.5 \pm 13.4$ & $85.8 \pm 13.8$ & $79.2 \pm 14.1$ & .35 \\
\hline Systolic blood pressure, mm Hg & $144 \pm 23$ & $141 \pm 19$ & $155 \pm 24$ & $145 \pm 34$ & .08 \\
\hline Diastolic blood pressure, $\mathrm{mm} \mathrm{Hg}$ & $81 \pm 12$ & $81 \pm 15$ & $91 \pm 12$ & $79 \pm 9$ & .02 \\
\hline $\mathrm{pH}$ & $7.413 \pm 0.031$ & $7.419 \pm 0.028$ & $7.406 \pm 0.02$ & $7.421 \pm 0.032$ & .31 \\
\hline $\mathrm{P}_{\mathrm{aO}_{2}}, \mathrm{~mm} \mathrm{Hg}$ & $78.1 \pm 10.8$ & $81.2 \pm 12.1$ & $85.9 \pm 12.4$ & $86.4 \pm 9.3$ & .045 \\
\hline $\mathrm{P}_{\mathrm{aCO}_{2}}, \mathrm{~mm} \mathrm{Hg}$ & $38.0 \pm 4.3$ & $37.3 \pm 5.3$ & $38.6 \pm 4.4$ & $36.1 \pm 3.7$ & .30 \\
\hline $\mathrm{HCO}_{3}^{-}, \mathrm{mM} / \mathrm{L}$ & $24.2 \pm 2.7$ & $24.0 \pm 3.0$ & $24.2 \pm 2.3$ & $23.4 \pm 1.9$ & .65 \\
\hline Lactate, $\mathrm{mM} / \mathrm{L}$ & $1.5 \pm 0.5$ & $1.7 \pm 0.5$ & $1.5 \pm 0.6$ & $1.7 \pm 0.5$ & .23 \\
\hline Norepinephrine, ng/mL & $0.70 \pm 0.3$ & $0.70 \pm 0.35$ & $0.66 \pm 0.21$ & $0.66 \pm 0.34$ & .84 \\
\hline Epinephrine, ng/mL & $0.22 \pm 0.2$ & $0.22 \pm 0.27$ & $0.18 \pm 0.19$ & $0.17 \pm 0.11$ & .83 \\
\hline
\end{tabular}

Table 2. $\quad P$ Values* for Group Comparisons of Baseline Data

\begin{tabular}{|c|c|c|c|c|c|c|}
\hline & \multicolumn{6}{|c|}{ Group Comparison } \\
\hline & A vs B & A vs $\mathrm{C}$ & A vs D & $\mathrm{B}$ vs $\mathrm{C}$ & B vs D & $\mathrm{C}$ vs $\mathrm{D}$ \\
\hline Body weight & .15 & .001 & $<.001$ & .28 & .008 & .46 \\
\hline Body mass index & .55 & .009 & $<.001$ & .22 & .041 & .87 \\
\hline $\mathrm{FEV}_{1}$ & .08 & .12 & $<.001$ & .99 & $<.001$ & $<.001$ \\
\hline Percent-of-predicted $\mathrm{FEV}_{1}$ & .23 & .31 & $<.001$ & .99 & $<.001$ & $<.001$ \\
\hline Percent-of-predicted FVC & .13 & 1.0 & $<.001$ & .13 & .14 & $<.001$ \\
\hline Diastolic blood pressure & 1.0 & .07 & .96 & .07 & .96 & .02 \\
\hline $\mathrm{P}_{\mathrm{aO}_{2}}$ & .79 & .10 & .07 & .50 & .40 & .99 \\
\hline
\end{tabular}

and/or leg fatigue, or notable electrocardiogram changes (ST segment depression $>2 \mathrm{~mm}$ or a short run of premature ventricular contractions). We subsequently divided the subjects into quartile groups based on peak oxygen uptake: group $\mathrm{A} \leq 623 \mathrm{~mL} / \mathrm{min}$, group B $665-803 \mathrm{~mL} /$ min, group C 829-1,037 mL/min, group $\mathrm{D} \geq 1,040 \mathrm{~mL} /$ min), as described previously. ${ }^{13}$ Arterial blood samples were drawn from an indwelling radial artery cannula, after local anesthesia, before exercise testing, with the subject sitting, during the last $15 \mathrm{~s}$ of each exercise stage, and at peak exercise. Arterial blood gases and lactate were immediately measured (ABL-800, Radiometer, Brønshøj, Denmark) in the exercise testing room. Plasma catecholamines (norepinephrine and epinephrine) were mea- sured via high-pressure liquid chromatography. The lactate threshold and norepinephrine threshold were calculated via log-log transform of the lactate-oxygen uptake and norepinephrine-oxygen uptake relationships. ${ }^{22} \mathrm{We}$ also calculated:

Dyspnea index $(\%)=$ minute ventilation $(\mathrm{L} / \mathrm{min})$ at peak exercise/maximal voluntary ventilation $(\mathrm{L} / \mathrm{min}) \times 100$

Breathing reserve $(\mathrm{L} / \mathrm{min})=$ maximal voluntary ventilation $(\mathrm{L} / \mathrm{min})$ - minute ventilation $(\mathrm{L} / \mathrm{min})$ at peak exercise

Heart rate reserve (beats $/ \mathrm{min})=$ predicted maximum heart rate - heart rate at peak exercise

$\mathrm{P}_{\mathrm{aO}_{2}}$ slope $(\mathrm{mm} \mathrm{Hg} / \mathrm{L})=$ difference in $\mathrm{P}_{\mathrm{aO}_{2}}$ /difference in oxygen uptake between at rest and at peak exercise 
Differences in Physiological Response to Exercise in Patients With Different COPD Severity

Table 3. Peak Exercise Data

\begin{tabular}{|c|c|c|c|c|c|}
\hline & \multicolumn{4}{|c|}{ Peak Oxygen Uptake Range, mL/min } & \multirow{2}{*}{$P$} \\
\hline & $\begin{array}{l}318-623 \\
\text { Group A }\end{array}$ & $\begin{array}{l}665-803 \\
\text { Group B }\end{array}$ & $\begin{array}{c}829-1,037 \\
\text { Group C }\end{array}$ & $\begin{array}{c}1,040-1,487 \\
\text { Group D }\end{array}$ & \\
\hline Oxygen uptake, $\mathrm{mL} / \mathrm{kg} / \mathrm{min}$ & $10.8 \pm 2$ & $13.8 \pm 1.7$ & $16.4 \pm 3.5$ & $19.4 \pm 2.8$ & $<.001$ \\
\hline Work load, watts & $28.6 \pm 8.3$ & $40.4 \pm 11.5$ & $53.9 \pm 8.4$ & $67.2 \pm 10.1$ & $<.001$ \\
\hline Borg dyspnea score & $6.1 \pm 2.1$ & $5.7 \pm 2.1$ & $7.0 \pm 2.3$ & $6.8 \pm 2.9$ & .07 \\
\hline Exercise time, $\mathrm{s}$ & $294 \pm 90$ & $432 \pm 120$ & $588 \pm 114$ & $726 \pm 108$ & $<.001$ \\
\hline Tidal volume, mL & $842 \pm 180$ & $1072 \pm 147$ & $1129 \pm 204$ & $1546 \pm 238$ & $<.001$ \\
\hline Breathing frequency, breaths/min & $31.2 \pm 6.7$ & $32.8 \pm 6.7$ & $34.7 \pm 5.6$ & $32.6 \pm 4.3$ & .28 \\
\hline Minute ventilation, $\mathrm{L} / \mathrm{min}$ & $25.4 \pm 5.5$ & $34 \pm 5.8$ & $38.1 \pm 6.2$ & $49.8 \pm 9.9$ & $<.001$ \\
\hline Breathing reserve, $\mathrm{L} / \mathrm{min}$ & $1.1 \pm 6.7$ & $1.6 \pm 7.6$ & $-3.3 \pm 8.8$ & $4.1 \pm 13.5$ & 0.08 \\
\hline Dyspnea index, $\%$ & $100.6 \pm 26.4$ & $100.3 \pm 24.9$ & $117.6 \pm 28.1$ & $99 \pm 25$ & 0.06 \\
\hline Ventilatory equivalent for $\mathrm{O}_{2}$ & $50.4 \pm 9.5$ & $46.8 \pm 8.2$ & $41.8 \pm 8.3$ & $41.4 \pm 7.0$ & $<.001$ \\
\hline Ventilatory equivalent for $\mathrm{CO}_{2}$ & $52.3 \pm 8.5$ & $46.5 \pm 7.1$ & $39.1 \pm 6.8$ & $38.3 \pm 5.7$ & $<.001$ \\
\hline Heart rate, beats/min & $114.1 \pm 19.1$ & $114.3 \pm 14.4$ & $133.8 \pm 18$ & $124.8 \pm 15.3$ & $<.001$ \\
\hline Heart rate reserve, beats/min & $35.1 \pm 20.0$ & $36.8 \pm 14.5$ & $16.8 \pm 17.9$ & $26.3 \pm 17.2$ & $<.001$ \\
\hline Systolic blood pressure, mm Hg & $193 \pm 33$ & $196 \pm 31$ & $213 \pm 37$ & $207 \pm 33$ & .18 \\
\hline Diastolic blood pressure, $\mathrm{mm} \mathrm{Hg}$ & $102 \pm 26$ & $98 \pm 25$ & $110 \pm 17$ & $94 \pm 17$ & .09 \\
\hline $\mathrm{pH}$ & $7.367 \pm 0.034$ & $7.364 \pm 0.045$ & $7.329 \pm 0.044$ & $7.360 \pm 0.045$ & .02 \\
\hline $\mathrm{P}_{\mathrm{aO}_{2}}, \mathrm{~mm} \mathrm{Hg}$ & $59.3 \pm 7.0$ & $67.4 \pm 12.7$ & $68.9 \pm 14.8$ & $67.6 \pm 11.5$ & .03 \\
\hline $\mathrm{P}_{\mathrm{aCO}_{2}}, \mathrm{~mm} \mathrm{Hg}$ & $42.6 \pm 4.4$ & $41.4 \pm 5.7$ & $43.6 \pm 8$ & $38.7 \pm 5.2$ & .043 \\
\hline $\mathrm{HCO}_{3}^{-}, \mathrm{mM} / \mathrm{L}$ & $24.4 \pm 2.3$ & $23.4 \pm 2.7$ & $22.7 \pm 3.1$ & $21.6 \pm 2.2$ & .005 \\
\hline Lactate, $\mathrm{mM} / \mathrm{L}$ & $2.8 \pm 0.8$ & $3.7 \pm 1.3$ & $4.7 \pm 1.6$ & $4.6 \pm 1.3$ & $<.001$ \\
\hline Norepinephrine, $\mathrm{ng} / \mathrm{mL}$ & $1.73 \pm 1.04$ & $1.99 \pm 1.39$ & $2.89 \pm 1.76$ & $2.21 \pm 1.19$ & .04 \\
\hline Epinephrine, ng/mL & $0.42 \pm 0.5$ & $0.35 \pm 0.32$ & $0.47 \pm 0.49$ & $0.25 \pm 0.16$ & .58 \\
\hline$\Delta$ Norepinephrine/ $\Delta$ oxygen uptake, $\mathrm{ng} / \mathrm{mL} / \mathrm{L} / \mathrm{min}$ & $0.38 \pm 0.33$ & $0.29 \pm 0.21$ & $0.34 \pm 0.30$ & $0.17 \pm 0.12$ & .04 \\
\hline$\Delta \mathrm{pH} / \Delta$ oxygen uptake, $\mathrm{L} / \mathrm{min}$ & $-0.164 \pm 0.108$ & $-0.119 \pm 0.066$ & $-0.115 \pm 0.056$ & $0.069 \pm 0.031$ & $<.001$ \\
\hline $\mathrm{P}_{\mathrm{aO}_{2}}$ slope, $\mathrm{mm} \mathrm{Hg} / \mathrm{L} / \mathrm{min}$ & $-78.5 \pm 69.7$ & $-30.1 \pm 21.0$ & $-26.6 \pm 25.1$ & $-20.8 \pm 11.0$ & $<.001$ \\
\hline$\Delta \mathrm{P}_{\mathrm{aCO}_{2}} / \Delta$ oxygen uptake, $\mathrm{mm} \mathrm{Hg} / \mathrm{L} / \mathrm{min}$ & $1.82 \pm 1.55$ & $0.87 \pm 0.78$ & $0.75 \pm 0.77$ & $0.30 \pm 0.40$ & $<.001$ \\
\hline
\end{tabular}

$\overline{\text { Values are mean } \pm \text { SD }}$

$\Delta$ Norepinephrine $/ \Delta$ oxygen uptake $(\mathrm{ng} / \mathrm{mL} / \mathrm{L} / \mathrm{min})=$ change in norepinephrine/difference between oxygen uptake at rest and at peak exercise

$\Delta \mathrm{P}_{\mathrm{aCO}_{2}} / \Delta$ oxygen uptake $(\mathrm{mm} \mathrm{Hg} / \mathrm{L})=$ change in $\mathrm{P}_{\mathrm{aCO}} /$ difference between oxygen uptake at rest and at peak exercise

Dyspnea was measured with the Borg scale. ${ }^{23}$ Before testing, the Borg scale was explained and its end points were anchored: 0 indicates "no difficulty in breathing" and 10 indicates "the most severe difficulty in breathing" that the subject had previously experienced or could imagine. The subjects rated dyspnea at rest, every minute during exercise, and at peak exercise. Immediately after exercise cessation and the completion of mechanical measurements, the subjects were asked for their reason(s) for exercise termination (dyspnea, leg fatigue, both, or other).

\section{Statistical Analysis}

Statistical analyses were performed with statistics software (JMP 9, SAS Institute, Cary, North Carolina). Data are reported as mean $\pm \mathrm{SD}$. We used parametric one-way analysis of variance for the normally distributed variables, and the non-parametric Kruskal Wallis test for the nonnormally distributed variables to determine differences in physiologic parameters between the 4 groups. Differences between pairs of groups were analyzed with the TukeyKramer honest significant difference post hoc test. The relationships between norepinephrine and the exercise testing parameters were assessed with Pearson correlation coefficients and linear regression analysis. Differences were considered significant when $P$ was $<.05$.

\section{Results}

In general, the 91 subjects were elderly $(69.7 \pm 6.8 \mathrm{y})$, slender (BMI $21.0 \pm 3.7 \mathrm{~kg} / \mathrm{m}^{2}$ ), and had emphysematous type COPD, according to the radiographic findings in most cases. Only 12 subjects had chronic bronchitis. These are common features among COPD patients in Japan. The subjects had a range of mild to very severe obstruction $\left(\mathrm{FEV}_{1} 1.06 \pm 0.45 \mathrm{~L}\right.$, percent-of-predicted $\mathrm{FEV}_{1}$ 
$\left.40.8 \pm 16.1 \%, \mathrm{FEV}_{1} / \mathrm{FVC} 0.44 \pm 0.10\right)$, and GOLD stages of 1 (5 subjects), 2 (15 subjects), 3 (49 subjects), and 4 (22 subjects). Subjects stopped cardiopulmonary exercise testing due to breathlessness in 53 tests (59\%), leg fatigue in 14 tests $(15 \%)$, and breathlessness and leg fatigue in 24 tests $(26 \%)$.

We divided the 91 subjects into quartile groups according to their peak oxygen uptake status:

Group A: $\leq 623 \mathrm{~mL} / \mathrm{min}, 22$ subjects

Group B: $665-803 \mathrm{~mL} / \mathrm{min}, 23$ subjects

Group C: $829-1,037 \mathrm{~mL} / \mathrm{min}, 23$ subjects

Group D: $\geq 1,040 \mathrm{~mL} / \mathrm{min}, 23$ subjects

Table 1 shows the baseline physiologic data. $\mathrm{FEV}_{1}$ and percent-of-predicted $\mathrm{FEV}_{1}$ were significantly reduced, and BMI was significantly lower among subjects with reduced exercise capacity. Table 2 shows the $P$ values for the group comparisons of the baseline data. $\mathrm{FEV}_{1}$ and percentof-predicted $\mathrm{FEV}_{1}$ in group D were significantly higher than in groups $\mathrm{A}, \mathrm{B}$, and $\mathrm{C}$. The BMI of group $\mathrm{A}$ was significantly lower than that of groups $\mathrm{C}$ and $\mathrm{D}$.

\section{Peak Exercise Results}

Table 3 shows the peak exercise results.

Ventilation. There were no differences in dyspnea score at peak exercise between the 4 groups, regardless of their exercise capacity. The 4 groups showed a similar increase in tidal volume in response to the increase in oxygen uptake during incremental exercise (Fig. 1). This increase in tidal volume peaked at a low level, with reduced exercise capacity, and the tidal volume and minute ventilation at peak exercise were significantly associated with peak oxygen uptake $\left(\mathrm{r}^{2}=0.64, P<.001\right.$, and $\mathrm{r}^{2}=0.65$, $P<.001$, respectively).

Table 4 shows the $P$ values for the group comparisons of peak exercise results. There were significant differences between all pairs except groups B and C. The expansion of tidal volume during exercise was extremely limited in the subjects with the most severely reduced exercise capacity (group A). On the other hand, the breathing frequency at peak exercise showed no significant differences between the 4 groups. However, it varied among the subjects: 26 subjects (29\%) had an elongated expiratory period (breathing frequency $<30$ breaths/min), 51 (56\%) had normal breathing (30-40 breaths/min), and $14(15 \%)$ had rapid and shallow breathing ( $>40$ breaths/min). In all groups, breathing reserve was $<10 \mathrm{~L} / \mathrm{min}$ and dyspnea index was around $100 \%$, which indicates that the exercise limitation was mainly caused by ventilatory disorders.

Gas Exchange. During peak exercise the ventilatory equivalents for oxygen and carbon dioxide remained high in group A. The ventilatory equivalents for oxygen was
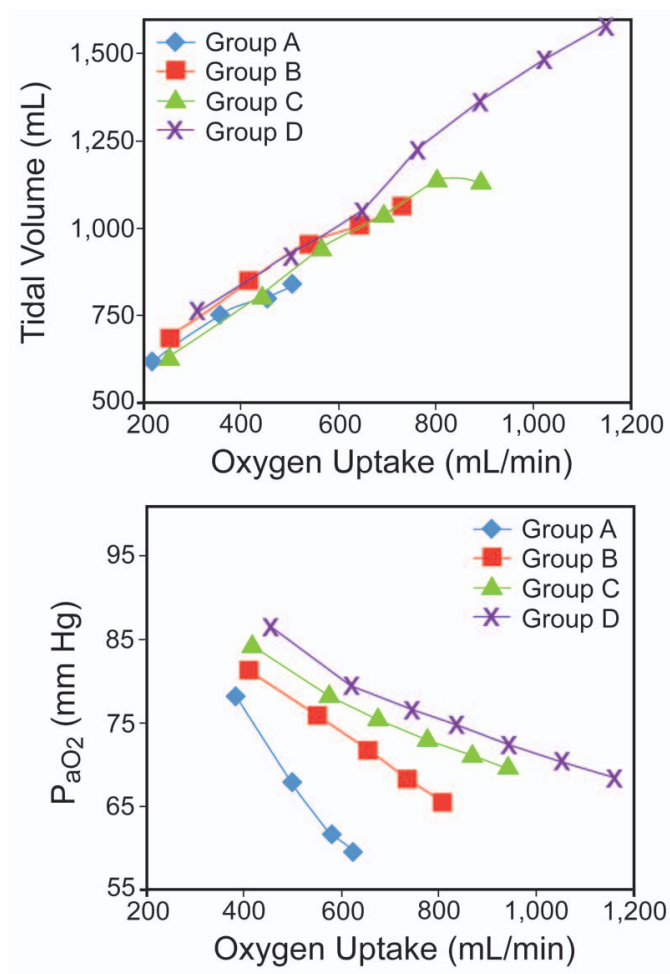

$\begin{array}{lllllll}\text { A } n=22 & 22 & 22 & 22 & & & \\ \text { B } n=23 & 23 & 23 & 22 & 20 & & \\ \text { C } n=23 & 23 & 23 & 23 & 23 & 18 & \\ \text { D } n=23 & 23 & 22 & 23 & 22 & 22 & 18\end{array}$

Fig. 1. Oxygen uptake versus tidal volume and $\mathrm{P}_{\mathrm{aO}_{2}}$ during incremental exercise testing. $n=$ number of subjects in each group at rest and at each exercise stage. $\mathrm{P}_{\mathrm{aO}_{2}}$ slope is calculated as the difference in $\mathrm{P}_{\mathrm{aO}_{2}}$ divided by the difference between oxygen uptake at rest and at peak exercise. The mean $\pm \mathrm{SD} \mathrm{P}_{\mathrm{aO}_{2}}$ slopes are: group $\mathrm{A}-78 \pm 70 \mathrm{~mm} \mathrm{Hg} \mathrm{L/min}$, group $\mathrm{B}-30 \pm 21 \mathrm{~mm} \mathrm{Hg} \mathrm{L/}$ min; group C $-27 \pm 25 \mathrm{~mm} \mathrm{Hg} \mathrm{L} / \mathrm{min}$; group D $-21 \pm 11 \mathrm{~mm} \mathrm{Hg} \mathrm{L/}$ min. Via Kruskal-Wallis test, $P<.001$. Via Tukey-Kramer honestsignificant-difference test (pair-wise comparison), $P<.001$ for group A vs group B, group A vs group C, and group A vs group D.

more impaired in group $\mathrm{A}$ than in group $\mathrm{C}$ or $\mathrm{D}$, but not more impaired than in group $\mathrm{B}$. The ventilatory equivalent for $\mathrm{CO}_{2}$ was more impaired in group $\mathrm{A}$ than in all other groups, but was also impaired in group $\mathrm{B} . \mathrm{P}_{\mathrm{aO}_{2}}$ linearly decreased in response to the increase in oxygen uptake during exercise $\left(\mathrm{P}_{\mathrm{aO}_{2}}\right.$ slope). Steep $\mathrm{P}_{\mathrm{aO}_{2}}$ slope was also an important feature in group $\mathrm{A}$. While it varied substantially among individuals, the steepest slope was in group A (see Fig. 1).

Exercise-Induced Acidosis and Contributing Factors. We examined the changes in mean plasma lactate, $\mathrm{P}_{\mathrm{aCO}_{2}}$, arterial $\mathrm{pH}$, and standard $\mathrm{HCO}_{3}{ }^{-}$from the at-rest stage to the end of each exercise stage (Fig. 2). Lactate was elevated beyond the inflection point (lactic threshold), but the lactate increase was lower in group A than in groups $\mathrm{C}$ $(P<.001)$ and $\mathrm{D}(P<.001)$. Moreover, the decrease in $\mathrm{HCO}_{3}{ }^{-}$related to lactic acidosis was not detectable in 
Table 4. $\quad P$ Values for Group Comparisons of Peak Exercise Data

\begin{tabular}{|c|c|c|c|c|c|c|}
\hline & \multicolumn{6}{|c|}{ Group Comparison } \\
\hline & A vs $B$ & A vs $\mathrm{C}$ & A vs D & B vs $\mathrm{C}$ & B vs D & $\mathrm{C}$ vs $\mathrm{D}$ \\
\hline Work load & $<.001$ & $<.001$ & $<.001$ & $<.001$ & $<.001$ & $<.001$ \\
\hline Exercise time & $<.001$ & $<.001$ & $<.001$ & $<.001$ & $<.001$ & $<.001$ \\
\hline Tidal volume & $<.001$ & $<.001$ & $<.001$ & .76 & $<.001$ & $<.001$ \\
\hline Minute ventilation & $<.001$ & $<.001$ & $<.001$ & .21 & $<.001$ & $<.001$ \\
\hline Ventilatory equivalent for $\mathrm{O}_{2}$ & .48 & .004 & .003 & .17 & .13 & .99 \\
\hline Ventilatory equivalent for $\mathrm{CO}_{2}$ & .03 & $<.001$ & $<.001$ & .004 & .001 & .98 \\
\hline Heart rate & 1.0 & .001 & .15 & .001 & .15 & .28 \\
\hline Heart rate reserve & .99 & .004 & .33 & .001 & .18 & .26 \\
\hline $\mathrm{pH}$ & .99 & .03 & .96 & .042 & .99 & .09 \\
\hline $\mathrm{P}_{\mathrm{aO}_{2}}$ & .11 & .04 & .10 & .98 & 1.0 & .98 \\
\hline $\mathrm{P}_{\mathrm{aCO}}$ & .89 & .95 & .14 & 60 & .45 & .04 \\
\hline $\mathrm{HCO}_{3}^{-}$ & .64 & .16 & .003 & .79 & .08 & .46 \\
\hline Lactate & .10 & $<.001$ & $<.001$ & .05 & .07 & .99 \\
\hline Norepinephrine & .92 & .029 & .65 & .12 & .95 & .34 \\
\hline$\Delta$ Norepinephrine/ $\Delta$ oxygen uptake & .51 & .95 & .03 & .82 & .50 & .11 \\
\hline$\Delta \mathrm{pH} / \Delta$ oxygen uptake & .14 & .10 & $<.001$ & .99 & .09 & .12 \\
\hline $\mathrm{P}_{\mathrm{aO}_{2}}$ slope & $<.001$ & $<.001$ & $<.001$ & .99 & .84 & .95 \\
\hline$\Delta \mathrm{P}_{\mathrm{aCO}_{2}} / \Delta$ oxygen uptake & .007 & .002 & $<.001$ & .97 & .19 & .39 \\
\hline
\end{tabular}

groups A and B, which indicates that lactate failed to reach the point that causes lactic acidosis. However, the value of arterial $\mathrm{pH}$ steeply decreased and $\mathrm{P}_{\mathrm{aCO}}$ rapidly increased early during exercise in group A.

Table 5 shows the correlations between $\mathrm{P}_{\mathrm{aCO}}$, lactate, $\mathrm{pH}$, and exercise stage. The $\mathrm{pH}$ at rest, and after stages 1 and 2 was significantly correlated with $\mathrm{P}_{\mathrm{aCO}}$, but not with lactate. Following stage 2 and at peak exercise, $\mathrm{pH}$ correlated with both lactate and $\mathrm{P}_{\mathrm{aCO}}$. The $\mathrm{pH}$ decrease resulted from respiratory acidosis at the early stage (work load $\sim 20$ watts), and thereafter from combined respiratory and lactic acidosis. In groups $\mathrm{A}$ and $\mathrm{B}$, the $\mathrm{pH}$ at peak exercise was mainly due to carbon dioxide retention; however, it was influenced by both carbon dioxide retention and arterial lactate in groups $\mathrm{C}$ and $\mathrm{D}$ (see Table 5), which both had an increase in arterial lactate and a decrease in $\mathrm{HCO}_{3}{ }^{-}$, related to the increase in oxygen uptake, but carbon dioxide retention was not detected in group D (see Fig. 2).

Sympathetic Activation During Exercise. Norepinephrine increased rapidly when the ability to increase tidal volume became limited (Fig. 3). The nature of this response was similar to that observed for dyspnea in all 4 groups. The increase in norepinephrine, due to the increase in oxygen uptake ( $\Delta$ norepinephrine/ $\Delta$ oxygen uptake) was significantly $(P=.03)$ greater in group $\mathrm{A}$ than in group $\mathrm{D}$ (see Table 3 and Fig. 4). In exercise stage 2 (work load 20 watts) the mean dyspnea score $(4.0 \pm 2.5)$ and norepinephrine $(1.41 \pm 1.0 \mathrm{ng} / \mathrm{mL})$ were significantly $(P<.001$ and $P=.03)$ higher in group A than in group $\mathrm{D}(0.8 \pm 1.0$ and $0.83 \pm 0.41 \mathrm{ng} / \mathrm{mL}$, respectively), and were similar to those during exercise stage 5 (work load 50 watts) in group D (see Fig. 4).

Table 6 shows the correlations between norepinephrine and other variables at peak exercise. In group A norepinephrine at peak exercise significantly negatively correlated with body weight and $\mathrm{FEV}_{1}$, and positively correlated with diastolic blood pressure and norepinephrine at rest. It also significantly correlated with epinephrine, $\mathrm{S}_{\mathrm{pO}_{2}}$, and diastolic blood pressure at peak exercise. Epinephrine and diastolic blood pressure significantly correlated with $\mathrm{FEV}_{1}(\mathrm{r}=-0.54, P=.006$, and $\mathrm{r}=-0.68, P<.001)$ and breathing reserve $(\mathrm{r}=-0.41, P=.058$, and $\mathrm{r}=-0.65$, $P=.003)$. On the other hand, norepinephrine at peak exercise in group D was influenced by plasma lactate, heart rate reserve, $\mathrm{pH}$, and dyspnea index at peak exercise. In contrast, the correlation between dyspnea score and the norepinephrine at peak exercise was not significant. Epinephrine during exercise and at peak exercise varied greatly among the individuals, so no significant differences were detected among the 4 groups (see Table 3).

Relationship Between Dyspnea and Norepinephrine. Norepinephrine increased rapidly beyond the inflection point (norepinephrine threshold) during exercise. This response was similar to that of dyspnea score in all the 4 groups. Both factors increased more rapidly in subjects with reduced exercise capacity (see Fig. 4). Moreover, norepinephrine, even in group A, increased to levels similar to those of the other groups. There was a strong linear positive correlation (slope median 4.86, range 0.14-43.39) between norepinephrine and dyspnea score during exer- 

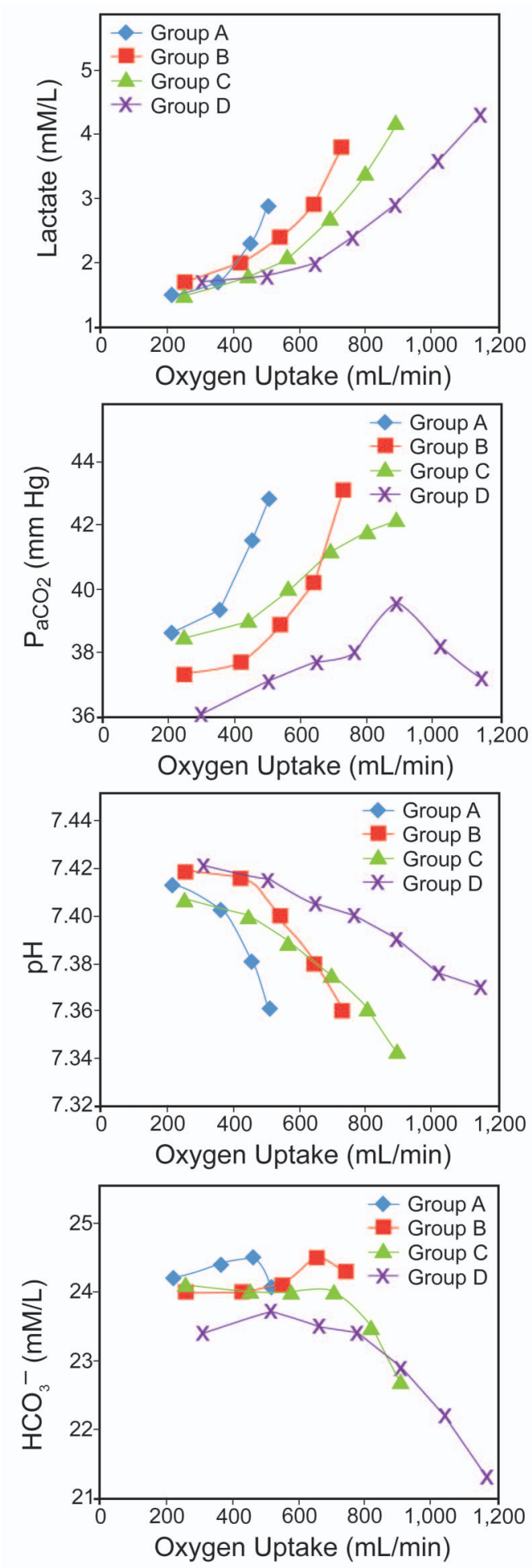
A $n=22$
B $n=23$
$22 \quad 22 \quad 22$
$\begin{array}{llll}23 & 23 & 22 & 20\end{array}$
C $n=23$
$23 \quad 23 \quad 23 \quad 23$
D $n=23 \quad 23 \quad 22 \quad 23 \quad 22 \quad 22$
18

Fig. 2. Changes in mean arterial plasma lactate, $\mathrm{P}_{\mathrm{aCO}}$, arterial $\mathrm{pH}$, and $\mathrm{HCO}_{3}{ }^{-}$, in COPD subjects during incremental exercise. $n=$ number of subjects in each group at rest and at each exercise stage. cise: $r^{2}$ median 0.96 , range $0.40-0.99$. The time points at which the subjects experienced breathing discomfort were also consistent $\left(\mathrm{r}^{2} 0.92, P<.001\right)$ with the threshold points of norepinephrine, regardless of their exercise capacity (Fig. 5). These findings suggest that exertional dyspnea might be objectively evaluated via norepinephrine level during exercise testing.

\section{Discussion}

We divided 91 clinically stable COPD subjects into quartile groups, according to peak oxygen uptake during cardiopulmonary exercise testing, and evaluated the differences in hypoxemia, acidosis, and sympathetic activation. These grouping values were similar to those in a previous study..$^{13}$ Peak oxygen uptake was extremely low in group A, whose survival prognosis is poor: peak oxygen uptake $<654 \mathrm{~mL} / \mathrm{min}$, 5-year survival rate $45 \%$, peak oxygen uptake $<10 \mathrm{~mL} / \mathrm{min} / \mathrm{kg}, 5$-year survival rate $35 \% .13,14$ Group A had severe to very severe obstruction, severe breathlessness at a low work load, and low BMI. On the basis of those results their poor prognosis is also predicted using the BODE (body mass index, air-flow obstruction, dyspnea, exercise capacity) index.. ${ }^{24}$ Specifically, the subjects with the most severely reduced exercise capacity (group A) had limited ability to increase ventilation; impaired gas exchange, especially exercise-induced rapid decrease in $\mathrm{P}_{\mathrm{aO}_{2}}$ (steep $\mathrm{P}_{\mathrm{aO}}$ slope), exercise-induced rapid increase in $\mathrm{P}_{\mathrm{aCO}}$, and progressive acidosis, but little change in lactic acidosis; and sympathetic activation at a low work load.

\section{Ventilatory Impairment}

The ability to increase tidal volume during exercise was limited, which limited exercise capacity in our subjects. O'Donnell et al ${ }^{25}$ described the mechanism of this limitation. They showed that dyspnea increases steeply once the inspiratory reserve volume falls to a critical level, preventing further increase of the tidal volume during constantwork-rate exercise. They also revealed that dyspnea increases with the disparity between the respiratory effort and tidal volume response.

\section{Gas-Exchange Abnormality}

While $\mathrm{P}_{\mathrm{aO}}$ slope differed substantially among individuals, it steepened with decreasing exercise capacity. It has also been reported that 6-min walk distance and oxygen desaturation (measured as $\mathrm{S}_{\mathrm{pO}_{2}}$ ) during the 6-min walk test are good predictors of long-term mortality in patients with COPD. ${ }^{26}$ However, in a previous study we found that the $\mathrm{P}_{\mathrm{aO}_{2}}$ slope was a significant independent prognostic factor for COPD, and was more closely associated with survival 
Differences in Physiological Response to Exercise in Patients With Different COPD Severity

Table 5. Correlation of $\mathrm{P}_{\mathrm{aCO}_{2}}$ and Lactate With Exercise Stage and Group

\begin{tabular}{|c|c|c|c|c|c|}
\hline \multirow[b]{2}{*}{ Exercise stage } & \multirow[t]{2}{*}{$\begin{array}{l}\text { Number } \\
\text { of } \\
\text { Subjects }\end{array}$} & \multicolumn{2}{|c|}{$\begin{array}{l}\text { Correlation With } \\
\qquad \mathrm{P}_{\mathrm{aCO}_{2}}\end{array}$} & \multicolumn{2}{|c|}{$\begin{array}{l}\text { Correlation With } \\
\text { Lactate }\end{array}$} \\
\hline & & $\mathrm{r}$ & $P$ & $\mathrm{r}$ & $P$ \\
\hline Rest & 91 & -0.50 & $<.001$ & & .58 \\
\hline 1 & 91 & -0.56 & $<.001$ & & .32 \\
\hline 2 & 90 & -0.61 & $<.001$ & & .40 \\
\hline 3 & 68 & -0.61 & $<.001$ & -0.32 & .009 \\
\hline 4 & 45 & -0.68 & $<.001$ & -0.36 & .01 \\
\hline 5 & 22 & -0.73 & $<.001$ & -0.66 & $<.001$ \\
\hline Peak exercise & 91 & -0.47 & $<.001$ & -0.60 & $<.001$ \\
\hline \multicolumn{6}{|c|}{ Peak exercise by group } \\
\hline Group A & 22 & -0.53 & .01 & & .25 \\
\hline Group B & 23 & -0.61 & .002 & & .20 \\
\hline Group C & 23 & -0.64 & .001 & -0.52 & .01 \\
\hline Group D & 23 & -0.72 & $<.001$ & -0.52 & .01 \\
\hline
\end{tabular}

time than was peak oxygen uptake or $\mathrm{S}_{\mathrm{pO}_{2}}$ slope. ${ }^{14}$ Furthermore, the $\mathrm{P}_{\mathrm{aO}}$ slope is a completely objective factor, whereas peak oxygen uptake or 6-min walk distance may be affected by patient motivation and other subjective factors. The results of this study again indicate that the $\mathrm{P}_{\mathrm{aO}}$ slope is a powerful indicator of pathogenetic mechanisms associated with severe exercise limitation and elevated mortality in COPD patients.

\section{Exercise-Induced Acidosis and Contributing Factors}

Arterial $\mathrm{pH}$ decreased to a similar level regardless of exercise capacity, but the decrease was more rapid in subjects with reduced exercise capacity. This progression of arterial acidemia was induced by both lactic acidosis and respiratory acidosis, but the relative contribution of each was different among subjects with different exercise capacities. In groups $\mathrm{C}$ and $\mathrm{D}, \mathrm{pH}$ at peak exercise was influenced by both carbon dioxide retention and arterial lactate level, because an increase in lactate and a decrease in $\mathrm{HCO}_{3}{ }^{-}$, related to the increase in oxygen uptake, were detected, and carbon dioxide retention was not detected in group D, like that in a healthy subject. ${ }^{11}$ However, the arterial $\mathrm{pH}$ at peak exercise was mainly due to carbon dioxide retention in groups $\mathrm{A}$ and $\mathrm{B}$, which could have been caused by limitation of increase of tidal volume (ie, the decrease in alveolar effective ventilation), and the effect of lactic acidosis was small.

\section{Sympathetic Activation During Exercise}

Group A subjects suffered from sympathetic activation at a low-intensity work rate in daily life, such as during eating, morning care, defecation, dressing, and bathing. These levels of sympathetic activation were similar to those at a high-intensity work rate in group D. The sympathetic nerve activity was largely related to obstructive and ventilatory disorders in group A, whereas it was mainly influenced by lactate, $\mathrm{pH}$, and the heart rate reserve in the other groups.

COPD is a systemic disease that negatively affects the cardiovascular and autonomic nerve systems. ${ }^{5}$ Cardiovascular disease and COPD are also intertwined. ${ }^{27,28}$ Cardiac events, including sudden death, are a common cause of death in patients with COPD. ${ }^{29}$ It is well known that enhanced sympathetic nerve activity, evidenced by elevated norepinephrine, is deleterious for the pathophysiology of chronic heart failure. ${ }^{6,30} \mathrm{We}$ suspect that sympathetic overactivity, which can be objectively evaluated as norepinephrine level during exercise, is one of the lifethreatening factors in COPD. However, the implication of sympathetic activation for COPD during exercise is inconclusive in this study and requires further investigation in detail.

\section{Relationship Between Dyspnea and Arterial Norepinephrine}

In the present study, dyspnea score and norepinephrine both increased rapidly after the increase of tidal volume became limited during exercise. One explanation is that the breathlessness during exercise was caused by difficulty in increasing the tidal volume in response to the respiratory motor drive resulting from lactic acidosis, hypercapnia, and/or hypoxemia. This, in turn, would likely necessitate greater breathing effort, which might stimulate the central sympathetic outflow in the brainstem. This hypothesis is supported by the fact that peak norepinephrine was significantly associated with both lactate and dyspnea index, and negatively correlated with $\mathrm{pH}$ and $\mathrm{S}_{\mathrm{pO}_{2}}$ 

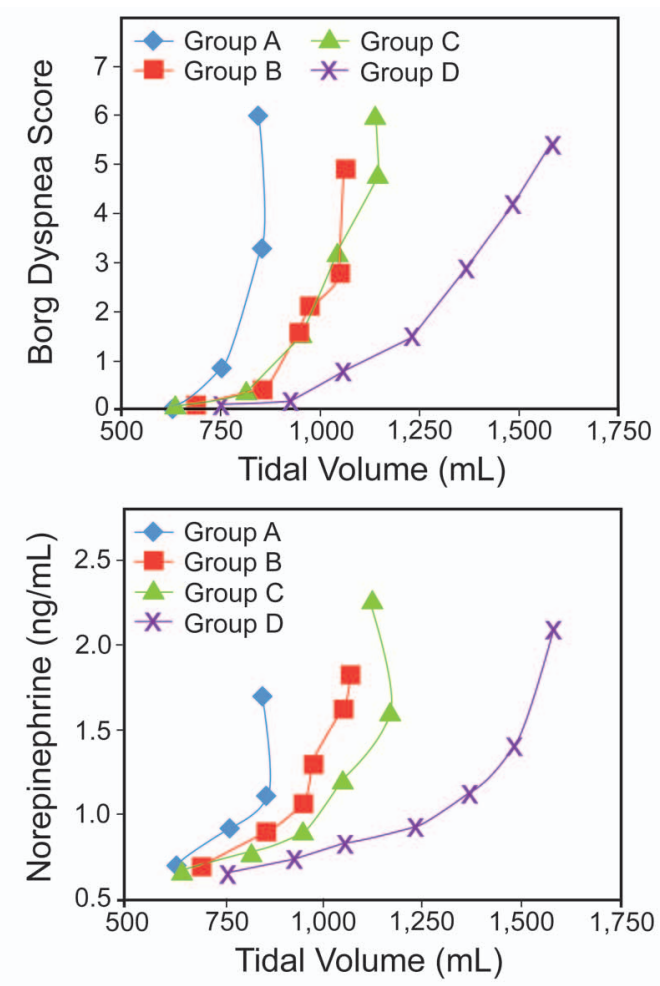

$\begin{array}{llllllll}\text { A } & n=22 & 22 & 22 & 20 & & & \\ \text { B } & n=23 & 23 & 23 & 22 & 20 & & \\ \text { C } & n=23 & 23 & 23 & 23 & 23 & 18 & \\ \text { D } & n=23 & 23 & 22 & 23 & 22 & 22 & 18\end{array}$

Fig. 3. Tidal volume versus Borg dyspnea score and arterial norepinephrine level during incremental exercise testing. $n=$ number of subjects in each group at rest and at each exercise stage.

(see Table 6). Dyspnea, respiratory motor drive, and autonomic control are tightly linked, both anatomically and functionally, in the brainstem. Specifically, the perception of respiratory discomfort is represented in the sensorimotor integration area of the limbic system, which governs autonomic control, ${ }^{31}$ and the central respiratory motor drive is associated with the central sympathetic outflow in the brainstem. ${ }^{32}$ These central interactions indicate that dyspnea and the increased respiratory drive in COPD may be pathophysiologically linked to heightened sympathetic activation, although the complexity of these interactions within the central nervous system make it difficult to clearly distinguish between cause and effect.

An intimate relationship between the increase in plasma norepinephrine and dyspnea intensity during exercise has also been observed in patients with other respiratory diseases, including idiopathic pulmonary fibrosis ${ }^{20}$ and sequelae of pulmonary tuberculosis. ${ }^{21}$ Also, Clark et $\mathrm{al}^{33}$ found that the administration of yohimbine increased norepinephrine release in healthy individuals, and this increase was associated with increased ventilatory response and an increased sensation of exertion during steady-state exercise. Thus, the increase in norepinephrine induced
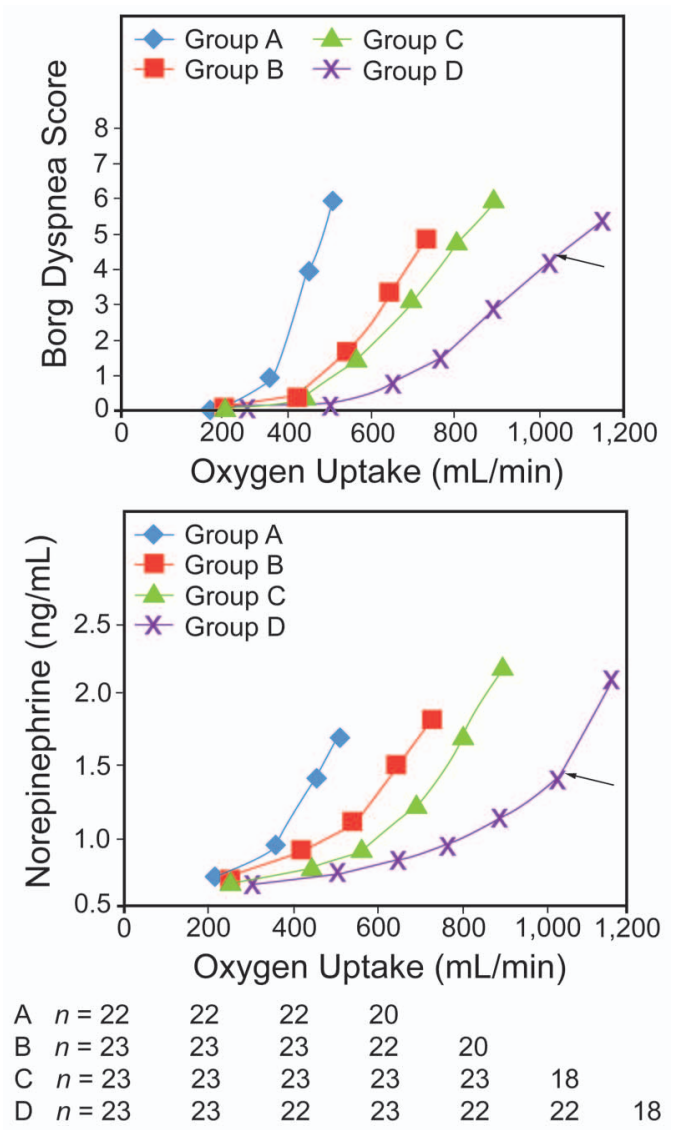

Fig. 4. Oxygen uptake versus Borg dyspnea score and the arterial norepinephrine level during incremental exercise testing. The arrows point to the end point of exercise stage 5 (work load 50 watts). $n=$ number of subjects in each group at rest and at each exercise stage. The arrows indicate the end point of exercise stage 5 (50 watts).

by exercise could also contribute to the increase in both ventilation and the sensation of breathlessness. Here, we only demonstrate that sympathetic activation, which was estimated norepinephrine increase, was closely correlated with dyspnea during incremental exercise. Further investigations are necessary to clarify whether the increase in dyspnea causes an increase in plasma norepinephrine, or whether the increase in plasma norepinephrine induces exertional dyspnea. However, regardless of the cause, our results demonstrate that exertional dyspnea can be objectively evaluated by measuring the plasma norepinephrine during exercise testing in patients with chronic respiratory diseases.

The exercise-induced hypoxemia, respiratory acidosis and sympathetic overactivity during exercise in COPD patients with severely reduced exercise capacity are associated with an elevated risk of mortality. These lifethreatening pathophysiological conditions could be improved by medication (eg, tiotropium ${ }^{34}$ and ghrelin $^{35}$ ) and/or pulmonary rehabilitation, including appropriate 
Table 6. Correlation of Peak Exercise Norepinephrine Level to Physiologic Variables

\begin{tabular}{|c|c|c|c|c|c|c|c|c|c|c|}
\hline & \multicolumn{8}{|c|}{ Peak Oxygen Uptake Range, $\mathrm{mL} / \mathrm{min}$} & \multirow{3}{*}{$\begin{array}{c}\text { Total } \\
N=91 \\
\mathrm{r}\end{array}$} & \multirow[b]{3}{*}{$P$} \\
\hline & \multicolumn{2}{|c|}{$\begin{array}{c}318-623 \\
\text { Group A } \\
n=22\end{array}$} & \multicolumn{2}{|c|}{$\begin{array}{c}665-803 \\
\text { Group B } \\
n=23\end{array}$} & \multicolumn{2}{|c|}{$\begin{array}{c}829-1,037 \\
\text { Group C } \\
n=23\end{array}$} & \multicolumn{2}{|c|}{$\begin{array}{c}1,040-1,487 \\
\text { Group D } \\
n=23\end{array}$} & & \\
\hline & $\mathrm{r}$ & $P$ & $\mathrm{r}$ & $P$ & $\mathrm{r}$ & $P$ & $\mathrm{r}$ & $P$ & & \\
\hline Body weight & -0.43 & .045 & 0.01 & & 0.05 & & -0.2 & & 0.00 & \\
\hline $\mathrm{FEV}_{1}$ & -0.50 & .02 & -0.12 & & 0.11 & & -0.35 & & -0.07 & \\
\hline Diastolic blood pressure & 0.66 & .001 & 0.22 & & 0.18 & & 0.36 & & 0.37 & $<.001$ \\
\hline Norepinephrine & 0.78 & $<.001$ & 0.86 & $<.001$ & 0.39 & & 0.49 & & 0.55 & $<.001$ \\
\hline Dyspnea index & 0.35 & & 0.30 & & 0.08 & & 0.55 & .007 & 0.33 & .001 \\
\hline Heart rate reserve & -0.34 & & -0.43 & .041 & -0.37 & & -0.73 & $<.001$ & -0.5 & $<.001$ \\
\hline Peak heart rate & 0.35 & & 0.26 & & 0.32 & & 0.73 & $<.001$ & 0.46 & $<.001$ \\
\hline Peak diastolic blood pressure & 0.47 & .03 & 0.37 & & 0.28 & & 0.05 & & 0.32 & .003 \\
\hline Peak pH & -0.38 & & -0.42 & .043 & -0.48 & .02 & -0.45 & .03 & -0.49 & $<.001$ \\
\hline Peak $\mathrm{S}_{\mathrm{pO}_{2}}$ & -0.59 & .004 & -0.12 & & -0.35 & & -0.12 & & -0.27 & .009 \\
\hline Peak lactate & 0.13 & & 0.62 & .002 & 0.45 & .03 & 0.73 & $<.001$ & 0.55 & $<.001$ \\
\hline Peak epinephrine & 0.72 & $<.001$ & 0.67 & $<.001$ & 0.49 & .02 & 0.29 & & 0.52 & $<.001$ \\
\hline
\end{tabular}

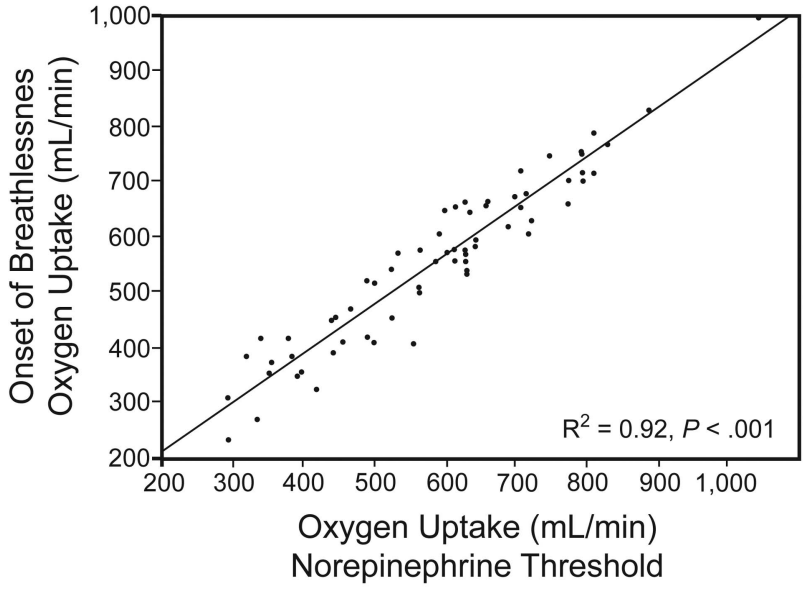

Fig. 5. Norepinephrine threshold versus onset of breathlessness in COPD subjects. Norepinephrine threshold was calculated using the log-log transform of the norepinephrine/oxygen uptake relationship. The time point of breathlessness onset (Borg dyspnea score $0.5-1$ ) and the threshold point are revealed by oxygen uptake.

oxygen supplementation, energy conservation, and work simplification using occupational therapy, in addition to improvements in ventilation and exercise capacity. However, our results (variation in the appearance of hypoxemia, respiratory acidosis, and/or sympathetic overactivity during exercise) highlight the importance of conducting cardiopulmonary exercise testing when determining the appropriate prescription for medication and pulmonary rehabilitation. On the basis of such evaluations, appropriate pulmonary rehabilitation, including exercise training and occupational therapy in daily living, can be prescribed. ${ }^{36}$ These interventions could be shown to improve the survival prognosis of COPD patients.

\section{Conclusions}

We divided the stable COPD subjects into quartile groups according to their peak oxygen uptake status and investigated relationships between, and changes in, lifethreatening factors such as hypoxemia, acidosis, and sympathetic activation during exercise, especially in those with most severely reduced exercise capacity (group A). The survival prognosis of these patients could be predicted to be very poor.

The mechanisms of exercise intolerance in COPD patients significantly varied among patients with different exercise capacities. Specifically, subjects with the most severely reduced exercise capacity (group A) had the characteristics of life-threatening factors, including impaired gas exchange, especially exercise-induced rapid decrease in $\mathrm{P}_{\mathrm{aO}}$ slopes; exercise-induced rapid increase in $\mathrm{P}_{\mathrm{aCO}_{2}}$ and progressive acidosis, but little change in lactic acidosis; and sympathetic activation at low work load. These life-threatening pathophysiological conditions could be improved by medication and/or pulmonary rehabilitation.

\section{ACKNOWLEDGMENTS}

We thank Eisei Oda MD, Medical Toukei Corporation, Tokyo, Japan, for assistance with statistical analysis.

\section{REFERENCES}

1. Nocturnal Oxygen Therapy Trial group. Continuous or nocturnal oxygen therapy in hypoxemic chronic obstructive lung disease. Ann Intern Med 1980;93(3):391-398.

2. Bott J, Carroll MP, Conway JH, Keilty SE, Ward EM, Brown AM, et al. Randomised controlled trial of nasal ventilation in acute ven- 


\section{Differences in Physiological Response to Exercise in Patients With Different COPD Severity}

tilatory failure due to chronic obstructive airways disease. Lancet 1993;341(8860):1555-1557.

3. Brochard L, Mancebo J, Wysocki M, Lofaso F, Conti G, Rauss A, et al. Noninvasive ventilation for acute exacerbations of chronic obstructive pulmonary disease. N Engl J Med 1995;333(13):817-822.

4. Chu CM, Chan VL, Lin AWN, Wong IWY, Leung WS, Lai CK. Readmission rates and life threatening events in COPD survivors treated with non-invasive ventilation for acute hypercapnic respiratory failure. Thorax 2004;59(12):1020-1025.

5. van Gestel AJR, Steier J. Autonomic dysfunction in patients with chronic obstructive pulmonary disease. J Thorac Dis 2010;2(4):215222.

6. Billman GE, Schwartz PJ, Stone HL. Baroreceptor reflex control of heart rate: a predictor of sudden cardiac death. Circulation 1982; 66(4):874-880.

7. Andreas S, Anker SD, Scanlon PD, Somers VK. Neurohumoral activation as a link to systemic manifestations of chronic lung disease. Chest 2005;128(5):3618-3624.

8. MacIntyre NR. Mechanisms of functional loss in patients with chronic lung disease. Respir Care 2008;53(9):1177-1184.

9. European Respiratory Society Task Force. Clinical exercise testing with reference to lung diseases: indications, standardization and interpretation strategies. Eur Respir J 1997;10(11):2662-2689.

10. Wasserman K, Hansen JE, Sue DY, Stringer W, Whipp BJ. Principles of exercise testing and interpretation, 4th edition. Philadelphia: Lippincott Williams \& Wilkins; 2005:41.

11. Weltman A, Wood CM, Womack CJ, Davis SE, Blumer JL, Alvarez $\mathrm{J}$, et al. Catecholamine and blood lactate responses to incremental rowing and running exercise. J Appl Physiol 1994;76(3):1144-1149.

12. Tanaka Y, Hino M, Morikawa T, Takeuchi K, Mizuno K, Kudoh S. Arterial blood lactate is a useful guide to when rehabilitation should be instigated in COPD. Respirology 2008;13(4):564-568

13. Oga T, Nishimura K, Tsukino M, Sato S, Hajiro T. Analysis of the factors related to mortality in chronic obstructive pulmonary disease/ role of exercise capacity and health status. Am J Respir Crit Care Med 2003;167(4):544-549.

14. Hiraga T, Maekura R, Okuda Y, Okamoto T, Hirotani A, Kitada S, et al. Prognostic predictors for survival in patients with COPD using cardiopulmonary exercise testing. Clin Physiol Funct Imaging 2003; 23(6):300-307.

15. Oga T, Tsukino M, Hajiro T, Ikeda A, Nishimura K. Predictive properties of different multidimensional staging systems in patients with chronic obstructive pulmonary disease. Int J Chron Obstruct Pulmon Dis 2011;6:521-526.

16. American Thoracic Society. Standards for the diagnosis and care of patients with chronic obstructive pulmonary disease. Am J Respir Crit Care Med 1995;152(5 Pt 2):S77-S121.

17. Pauwels RA, Buist AS, Calverley PM, Jenkins CR, Hurd SS. Global strategy for the diagnosis, management, and prevention of chronic obstructive pulmonary disease: NHLBI/WHO Global Initiative for Chronic Obstructive Lung Disease (GOLD) workshop summary. Am J Respir Crit Care Med 2001;163:1256-1276.

18. American Thoracic Society. Standardization of spirometry: 1987 update. Am Rev Respir Dis 1987;136(5):1285-1298.

19. American Thoracic Society. Standardization of spirometry, 1994 update. Am J Respir Crit Care Med 1995;152(3):1107-1136.

20. Miki K, Maekura R, Hiraga T, Hashimoto H, Kitada S, Miki M. Acidosis and raised norepinephrine levels are associated with exer- cise dyspnoea in idiopathic pulmonary fibrosis. Respirology 2009; 14(7):1020-1026.

21. Miki K, Maekura R, Hiraga T, Hashimoto H, Kitada S, Miki M. Exertional dyspnea-related acidotic and sympathetic responses in patients with sequelae of pulmonary tuberculosis. J Physiol Sci 2010; 60(3):187-193

22. Beaver WL, Wasserman K, Whipp BJ. Improved detection of lactate threshold during exercise using a log-log transformation. J Appl Physiol 1985;59(6):1936-1940.

23. Borg GA. Psychophysical basis of perceived exertion. Med Sci Sports Exerc 1982;14(5):377-381.

24. Celli BR, Cote CG, Marin JM, Casanova C, Montes de Oca M, Mendez RA. The body-mass index, airflow obstruction, dyspnea, and exercise capacity index in chronic obstructive pulmonary disease. N Engl J Med 2004;350(10):1005-1012.

25. O'Donnell DE, Hamilton AL, Webb KA. Sensory-mechanical relationships during high-intensity, constant-workrate exercise in COPD. J Appl Physiol 2006;101(4):1025-1035.

26. Casanova C, Cote C, Marin JM, Pinto-Plata V, de Torres JP, Aguirre-Jaíme A, et al. Distance and oxygen desaturation during the 6-min walk test as predictors of long-term mortality in patients with COPD. Chest 2008;134(4):746-752.

27. Sin DD, Man SF. Why are patients with chronic obstructive pulmonary disease at increased risk of cardiovascular diseases? The potential role of systemic inflammation in chronic obstructive pulmonary disease. Circulation 2003;107(11):1514-1519.

28. Hirotani A, Maekura R, Okuda Y, Yoshimura K, Moriguchi K, Kitada $\mathrm{S}$ et al. Exercise-induced electrocardiographic changes in patients with chronic respiratory diseases: differential diagnosis by 99mTc-tetrofosmin SPECT. J Nucl Med 2003;44(3):325-330

29. Celli B, Decramer M, Kesten S, Liu D, Mehra S, Tashkin DP. Mortality in the 4-year trial of tiotropium (UPLIFT) in patients with chronic obstructive pulmonary disease. Am J Respir Crit Care Med 2009;180(10):948-955.

30. Cohn JN, Levine TB, Olivari MT, Garberg V, Lura D, Francis GS, et al. Plasma norepinephrine as a guide to prognosis in patients with chronic congestive heart failure. N Engl J Med 1984;311(2):819-823.

31. Shields RW Jr. Functional anatomy of the autonomic nervous system. J Clin Neurophysiol 1993;10(1):2-13.

32. Zhong S, Zhou SY, Gebber GL, Barman SM. Coupled oscillators account for the slow rhythms in sympathetic nerve discharge and phrenic nerve activity. Am J Physiol 1997;272(4 Pt 2):R1314-R1324.

33. Clark AL, Galloway S, MacFarlane N, Henderson E, Aitchison T, McMurray JJ. Catecholamines contribute to exertional dyspnoea and to the ventilatory response to exercise in normal humans. Eur Heart J 1997;18(11):1829-1833.

34. Yoshimura K, Maekura R, Hiraga T, Kitada S, Miki K, Miki M, Tateishi Y. Effects of tiotropium on sympathetic activation during exercise in stable chronic obstructive pulmonary disease patients. Int J Chron Obstruct Pulmon Dis 2012;7:109-117.

35. Nagaya N, Itoh T, Murakami S, Oya H, Uematsu M, Miyatake K, Kangawa K. Treatment of cachexia with ghrelin in patients with COPD. Chest 2005;128(3):1187-1193.

36. ERS Task Force, Palange P, Ward SA, Carlsen KH, Casaburi R, Gallagher CG, et al. Recommendations on the use of exercise testing in clinical practice. Eur Respir J 2007;29(1):185-209. 